\title{
Article \\ The Role of Social Media in the Innovation and Performance of Kuwaiti Enterprises in the Food Sector
}

\author{
Rashed Salem Alhaimer
}

Citation: Alhaimer, R.S. The Role of Social Media in the Innovation and Performance of Kuwaiti Enterprises in the Food Sector. J. Theor. Appl. Electron. Commer. Res. 2021, 16 , 1960-1972. https://doi.org/10.3390/ jtaer16060110

Academic Editors: Agnieszka Głodowska and Krzysztof Wach

Received: 13 April 2021

Accepted: 22 June 2021

Published: 29 June 2021

Publisher's Note: MDPI stays neutra with regard to jurisdictional claims in published maps and institutional affiliations.

\begin{abstract}
This study examined social media's role in various levels of research, development, and performance within enterprises in Kuwait. The research incorporated four inductive case analyses in various sectors. The case studies epitomize the supply chain of Kuwaiti enterprises, including small and medium-sized enterprises (SMEs). Media richness theory and social exchange effectuation theory were utilized to create an effective theory and a theoretical framework. This study collected data via a questionnaire completed by 100 managers employed by Kuwaiti SMEs specialized in the food sector and interviews with eight managers. Numerical data were analyzed via SPSS software, while textual data were analyzed by applying thematic analysis. The results of this study suggest that Kuwaiti companies should adopt social media platforms and other novel, innovative outlets to publicize their organizations and maximize performance. Social media richness and openness tend to determine the supplier selection process in most Kuwaiti enterprises, leading to positive transactional and social impacts on entrepreneurship.
\end{abstract}

Keywords: social media richness; innovation; communication platform; influenced performance; interaction process

\section{Introduction}

Social media provides a platform for companies to connect with people from various backgrounds [1]. Moreover, it empowers companies to establish and reinforce their branding among a wider population or target a specific population [2]. Consequently, using many-to-many communication tools (i.e., social media) buttresses companies' innovation outcomes in terms of marketing [3]. However, companies should make wise use of innovative ideas on social media, as a poorly adopted branding campaign could rapidly destroy a company's reputation [4]. Thus, overreliance on social media is similar to trading on the stock market; the value of the company could go up or down in a matter of days. Hence, it is essential to practice calculated dependence on social media when adopting innovative ideas, as the consequences of using new methods related to branding, production, and the supply chain simultaneously spread to the whole population [5]. Therefore, adopting innovative social media strategies has a direct impact on organizational performance [6].

It should also be noted that embracing innovative ideas might not necessarily be effective in increasing organizational performance [7], and the negative consequences of innovation are termed innovation pathologies [8]. Companies fail in their attempts to adapt when managerial decisions related to the adoption of new ideas are made without considering a comprehensive corporate innovation strategy [9]. As such, managers may be tempted to use innovative methods in their companies based on insufficient information gathered from social media platforms [10]. Thus, engaging in financially efficient innovation requires decision makers to objectively examine information obtained from social media rather than rely on their own subjective beliefs formulated through particular forms of social media. For instance, a suggested way to examine the reliability of information extracted from social media is the use of metrics to examine the return on investment from using social media [11,12]. 
There are, in fact, various scenarios in which social media can lead to innovation or decrease the performance of companies. Social media platforms are numerous, and within each type of social media (e.g., Twitter, Facebook, and Instagram), people tend to gather in groups that reflect their interests. Hence, observing one group of people on social media with a particular interest may lead to the creation of eccentric views that hamper managers; thus, it is important to understand the demands and requirements of other categories on social media [12]. Accordingly, managers may tend to adopt innovative methods that satisfy one category of social media users (i.e., a group of people who have the same interest in social media, such as followers of one person or a group on Facebook comprising members who like organic foods) [13]. For instance, following the observation of a group of people who support natural foods, decision makers within a food company may tend to rely on embracing natural foods. Such an innovative step may prove disastrous from an economic viewpoint because a considerable proportion of the population may not consider purchasing natural foods due to their price or a lack of interest [14]. Thus, such an innovative decision would have an adverse effect on the company's performance, as it would not create real value and, hence, would not attract a substantial number of new customers [15].

Another point is that social media could trigger incorrect innovation decisions when there is no culture of innovation within a specific organization [16,17]. In reality, companies-except for cutting-edge technological companies-focus on daily production, which means innovation has lower priority. Indeed, the raison d'etre of all private organizations is to earn money; thus, in cases where innovation would not result in maximizing the profit of an organization (e.g., overcoming costs due to resistance to change and training courses on innovative methods), the adoption of innovative methods based on information extracted from social media could have adverse effects.

The results of various studies [18-21] indicate that social media plays a controversial role in innovation and organizational performance. For example, social media may lead to increased innovation; however, it could simultaneously lead to a decrease in company performance [22]. Similarly, the wise use of social media platforms by companies may result in an increase in performance without implementing innovative methods [23]. Furthermore, other studies $[5,21,24-26]$ have found that using social media could lead to both innovation and higher organizational performance among companies.

Accordingly, it can be deduced that mixed results can be extracted when examining the role of social media in the innovation and performance of companies. To tackle such conflicting results in the literature, this paper aims to explore the role of social media and innovation in the performance of Kuwaiti enterprises. As such, this study purposes to examine the effect of social media on the level of innovative capacity in SMEs and its effect on organizational performance. Moreover, it aims to examine whether increasing innovative capacity boosts the organizational performance of SMEs. To achieve these aims, several hypotheses are tested using data collected via a questionnaire completed by a sample of 100 managers employed by Kuwaiti enterprises. The hypotheses address the following research question: what role does social media play in the performance and innovation of enterprises in Kuwait?

\section{Literature Review}

Social exchange theory proposes that people make decisions based on unconscious or conscious calculations of the rewards and costs associated with taking a specific action. In these decisions, the goal is to maximize rewards and reduce costs. A practical application of this theory is companies' use of social media platforms to increase their gains. Through the use of social media, managers aim to identify the needs of customers and change their companies' organizational performance to meet such needs. When managers start using a social media platform, they tend to prefer the one that optimally serves their aims.

According to media richness theory, managers consider the capacity of information to shift the understanding and views of individuals within a time interval [27]. Neverthe- 
less, media platforms have varying capacities to disseminate information and encourage individuals to communicate, which is denoted as the richness of the medium used to provide information. Unlike traditional media, social media platforms are decentralized and empower any entity (i.e., private or public, as well as an individual or organization) to formulate and disseminate information to everyone using the same social media platform. Hence, according to this theory, social media is richer than traditional media. On the market level, the richness of social media, such as its ability to handle numerous information cues simultaneously, provide instant feedbacks, create a personal focus, and utilize natural language, has led companies to adopt it for reaching out to and changing the attitudes of customers. Moreover, company managers have tended to use social media platforms to change attitudes and behaviors at the individual and organizational levels. Such changes could, within the context of this paper, lead to changes in the innovative capacity and organizational performance of their companies. However, upholding media richness theory could trigger problems related to selecting the proper social platform. Company managers should consider issues related to media sensitivity and job performance, as well as the side effects of over-reliance on social media, such as the more frequent dissemination of negative advertisements about the company's performance, and determine ways to measure the return on investment from using social media to communicate with customers.

Although the potential benefits of social media use by Kuwaiti enterprises are significant, outcomes should never be assumed in any particular setting. As previous studies [1-3] have demonstrated, social media usually offers users real-time communication platforms that are more efficient and less costly than various traditional tools. As such, its use is appropriate for entrepreneurs. The extensive social interaction occurring across various social media platforms is continuously growing. Using such innovative tools as part of the entrepreneurship process could impact business relationships, both externally and internally. Therefore, it is vital to start by investigating some of the tools and analyzing their impact, particularly regarding Kuwaiti entrepreneurship.

Enterprises can use social media to create brand communities through fan pages to facilitate interactions with their customers [3], thereby facilitating personal relationships, brand reputation, and customer loyalty [11]. However, despite these advantages, there are several drawbacks. On social media sites, such as Twitter, customers expect a quick response, and failing to meet this expectation could offend current and potential customers [16].

Business enterprises can also promote new products and services on social media platforms. Consumers are increasingly using social media to make purchases, engage with sellers, and collect valuable insights from other customers [19]. This approach helps consumers play an active role in business innovation $[28,29]$. Social media provides users with the opportunity to voice their opinions and introduce new ideas, which could reduce in-house research and development expenses. Innovative ideas provided by users are transformed into new technical knowledge that builds upon the existing knowledge of business enterprises [7]. However, these innovative approaches are frequently debated. For example, one belief is that maintaining an open and collaborative mentality by including social media users rather than relying solely on highly qualified personnel yields innovation [26]. Social media provides a platform through which organizations can collect feedback from global consumers to design products beyond the initial conceptualizations [30]. This approach improves entrepreneurial innovation by simplifying coordinated actions and facilitating knowledge flow between external and internal sources. Social media can indeed provide global strategies for organizations to grow, and it can be inferred from the above that social media has a positive impact on entrepreneurial innovativeness. A previous study [31] examined the effect of using social media on organizational performance and employee's productivity in a sample of 140 participants within the context of Zimbabwe. They found that the role of social media is underrated due to resistance to change, the risks of using social media, and fears associated with implementing social media in the work process. However, participants found that using social media has increased employee productivity 
and supported communication amongst staff members [31]. The results of another study that included participants from Turkey, Poland, the United States (US), and China [32] reflect the importance of companies using social media to increase the level of communication in foreign markets, which, in turn, enhances organizational performance. Therefore, we propose the following hypothesis:

Hypothesis 1 (H1). The utilization of social media influences the performance of enterprises in the Kuwaiti context.

Virtual space provides an enormous platform, and its scope for spreading information helps enterprises increase their knowledge capacity [26]. Through social media, entrepreneurs become more dynamic in their approach and play a dominant role in connecting their organization with the external world [28]. Thus, enterprises discard outdated ideas and become more advanced by applying innovation to achieve a market advantage [29]. An example of entrepreneurial innovation is the capacity of enterprises to convert existing stock knowledge into new technical knowledge [18]. Innovation helps enterprises minimize investment risks and develop new approaches to lower in-house research costs [19].

From a management perspective, innovation can be divided into two categories: realized innovation and potential innovation [8]. Realized innovation involves knowledge related to exploitation and transformation. Knowledge transformation is the capability of an enterprise to combine existing knowledge with newly acquired knowledge. Knowledge exploitation is the process by which an organization extends, refines, and leverages existing competencies or develops new ones by acquiring and transforming outside knowledge [20]. Potential innovation deals with the acquisition and assimilation of knowledge. Knowledge acquisition is an enterprise's ability to recognize, give value to, and adapt useful external knowledge, while assimilation refers to the absorption of external knowledge. After collecting data from 92 SMEs in the textile industry sector, other researchers [33] found that establishing a culture of innovation through developing organizational learning capabilities has a positive effect on organizational innovative performance. Similarly, another study [34] collected data from 183 SMEs in the Indonesian context. The authors reported that innovation has a positive effect on company performance, and this effect is moderated by organizational culture and entrepreneurial orientation. Therefore, we propose the following hypothesis:

Hypothesis 2 (H2). Innovation positively influences the performance of enterprises in the Kuwaiti context.

The use of social media increases innovation in business enterprises. The existing research emphasizes the direct and indirect effects of innovation on organizational performance capability [3]. As an enterprise becomes more innovative, its chances of adjusting its internal organization and changing its internal environment to meet its needs through the exploitation of opportunities also increase [30]. Researchers [35] have also explored the role of social media as an innovative way to support organizational performance. They found that fewer companies mentioned that they do not use social media to support new product development. This is due to the absence of knowledge among companies about the differences between media sources and social media platforms. Ideally, innovation involves developing a product or service, meeting consumer needs, and using existing knowledge to design new products. According to Herden [36], innovation is a strategic creative action that involves developing new ideas and improving existing ones, and Dinesh and Sushil [37] suggested that collaboration with stakeholders helps organizations adopt new products and reduce product lifecycles. Innovation, performed with the help of external factors, originates from the knowledge circulation process of enterprises. This process of the inflow and outflow of knowledge helps to develop internal entrepreneurial innovation. Nevertheless, the simple acquisition and combination of new knowledge are 
insufficient for an innovative enterprise, as a virtual network system is also required [38]. New knowledge helps to legitimize and support the innovation process in the long term. Therefore, we propose the following hypothesis:

Hypothesis 3 (H3). Increasing social media use enhances the innovative capacity of enterprises in the Kuwaiti context.

In their study, Zhan et al. [15] emphasized that social media is likely to be used as a means of partner selection. In most cases, it provides monitoring platforms for entrepreneurs, where they can inspect their businesses, including their suppliers, via social media content. Social media platforms are also instrumental in gathering information about the reputation of business processes, including the supply chain. Comparing the various types of information available about entrepreneurs on social media is instrumental in choosing the most efficient suppliers. Thus, entrepreneurs can more effectively identify the pros and cons of businesses. Empirical research studies based on social media efficiency have demonstrated evidence of this notion.

In the context of entrepreneurship, social media research remains an evolving module, including the use of frameworks and theories that are somehow limited, given that most studies tend to be exploratory. The literature on information technology (IT) has effectively established social media as an aspect that creates a theoretical framework. While conducting social media research, it would be logical to incorporate cross-disciplinary theories to offer a complete picture of the phenomena being explored.

The theoretical perspectives incorporated into this analysis remain important since they are likely to improve the prediction of complex issues and their description. For instance, with respect to the use of social technologies for entrepreneurial relationships, this research blends various theories from previous studies to develop a theoretical lens that covers different research aspects. Furthermore, based on a systematic and structured social media review, it is evident that the theories, frameworks, and constructs typically used in social media contexts differ from those used within Kuwaiti enterprises. Moy et al. [7] insisted that this observation is expected, given that social media usually incorporates various psychosociological issues. Social exchange theory is frequently used as a research lens; therefore, it is difficult to separate this theory from technology use in entrepreneurship.

This research aimed to examine social media's role in various levels of research, development, and performance within enterprises in Kuwait. Using the conceptual framework shown in Figure 1, this study sought to explore social media utilization with respect to enterprise performance in the Kuwaiti context.

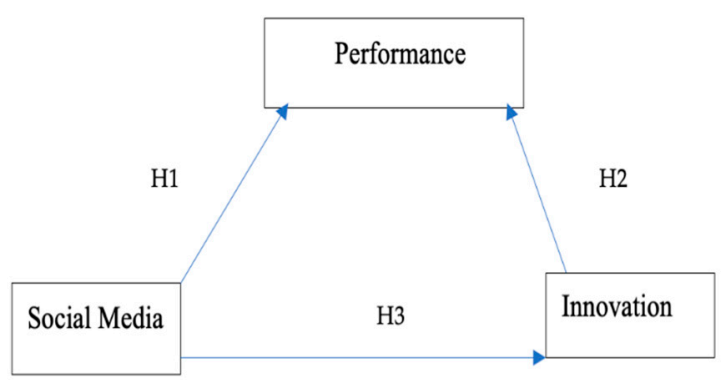

Figure 1. Conceptual framework.

The study's results reveal that innovation tends to have a positive influence on enterprises' performance in Kuwait. However, there are various limitations to this kind of research. For instance, researchers have conducted minimal work on this topic, making comparisons quite challenging. To resolve this issue, two empirical analyses published in operations management journals focused on social media operational efficiency were incorporated. This allowed us to analyze social media interactions in the context of enterprises' performance in Kuwait. 


\section{Methodology}

This study utilized a mixed-methods approach that incorporated interpretivism and positivism. Positivism was adopted to ensure objectivity in the process of collecting and analyzing data. Thus, from an ontological viewpoint, the researcher and the research phenomenon were separated from one another. From an epistemological viewpoint, the researcher interpreted the data objectively, as the data were analyzed statistically. Accordingly, the potential for researcher bias influencing the results was limited.

Based on social constructionism, interpretivism was incorporated to enhance the exploration of social media's role in Kuwaiti enterprises' performance. Performance tends to be based on various social factors, thus making this approach sensible for exploring the issue at length, especially from the persons' perspective, instead of quantifying the issues and losing valuable insights. It is essential to note that qualitative research, in this case, provided a holistic view of the studied phenomenon from managers employed by SMEs in Kuwait. This view included the entrepreneurship culture and the ways in which business is conducted in Kuwait. Typically, qualitative studies begin with an inductive approach by presenting data to drive a theory that might be used throughout the research.

The population of this study included all SMEs in Kuwait, but sampling focused on SMEs in the food sector. Moreover, the selected companies were active on popular social media platforms (e.g., Facebook, Instagram, You Tube, and Twitter) in Kuwait [39]. There were two different samples (i.e., one sample for the questionnaire and another for interviews).

This study used a questionnaire for data collection. Using a questionnaire enables the collection of data from a relatively large sample, which increases the reliability of the findings. Data were collected from 100 enterprises operating in the food sector (e.g., restaurants and food services) in Kuwait. According to Markaz, there are 30,000 SMEs in Kuwait [40]. Assuming that each enterprise has one manager, the overall population is 30,000 managers. Based on a sample calculator empowered by Qualtrics, the ideal sample size for this population is 384 managers if a confidence level of $95 \%$ and a margin of error of 5\% are adopted [41]. Although only 100 managers were recruited for the study, which represented a response rate of $26.04 \%$, such a response rate was sufficient, considering the difficulties of collecting data during the coronavirus disease 2019 (COVID-19) pandemic.

Managers employed by SMEs were recruited via messages sent to their email addresses, which were obtained from websites and social media platforms. A cost- and time-effective convenience sample approach was adopted for enterprise selection. The questionnaire and interview data were collected from September 2020 to November 2020. Interviews were conducted after administering the questionnaire, and triangulation was performed by analyzing both numerical and textual data.

It is also important to note that the interviews were conducted in the Arabic language to facilitate communication. After obtaining informed consent, the interviews were tape-recorded and then transcribed verbatim. Moreover, data were coded to prevent the interviews' essence from being lost, especially during translation. Eight managers were interviewed, which was sufficient to fulfil data saturation. Interviewees were selected using purposive sampling. The selected managers were the first participants to complete the questionnaire. Interview questions covered three main points (i.e., the use of social media in business, innovation based on social media findings, and their companies' performance following the adoption of social media). The collected textual data were analyzed using thematic analysis to identify codes and themes.

The questionnaire's structure was standardized and contained nine items related to the research topic. Each item was measured using a five-point Likert scale, where 1 denoted strongly agree and 5 denoted strongly disagree. The questions were categorized into three groups: social media sites, performance, and innovation (Table 1). Data representation was performed in this study by presenting the findings in tables to make them visually appealing and easy to comprehend. This study further used quotations from interview 
participants to support the discussion. Moreover, this study provided supplementary evidence based on the literature.

Table 1. The measures, descriptions, and sources of variables used in the questionnaire.

\begin{tabular}{ccc}
\hline Measure & Description & Source \\
\hline Social media sites & $\begin{array}{c}\text { Virtual platforms that allow } \\
\text { individuals to create public or } \\
\text { semi-public profiles. }\end{array}$ & {$[9]$} \\
\hline $\begin{array}{c}\text { Performance (primarily } \\
\text { related to innovation) }\end{array}$ & $\begin{array}{c}\text { Development of products or } \\
\text { services by enterprises using } \\
\text { the latest approaches. }\end{array}$ & {$[11]$} \\
\hline Innovation & $\begin{array}{c}\text { Ability of organizations to } \\
\text { acquire, combine, assimilate, } \\
\text { and exploit new knowledge } \\
\text { from external sources. }\end{array}$ & {$[10]$} \\
\hline
\end{tabular}

The cyclical development process of a qualitative study, including the iterative interaction among data analysis, collection, and theoretical development, as demonstrated in the above table and figure, is known as progressive focusing. In this case, the researchers argue that computer-assisted qualitative data acquisition software (CAQDAS) is instrumental, especially in maintaining the organization of non-linear qualitative data, and enhances the credibility and transparency of the research. The entirety of the research was conducted using CAQDAS with support of the Arabic language.

\section{Results}

Quantitative data were analyzed using SPSS software. In this study, performance was considered a dependent variable, and social media sites and innovation were considered independent variables. Regression was performed via SPSS for two reasons: ease of use and usefulness. According to the theory of acceptance model (TAM), users prefer technological services that they consider useful and easy to use. Thus, in comparison to structural equation modelling (SEM), SPSS regression is easy to use and simple in terms of the sequence of steps and the complexity of each step. Moreover, in terms of usefulness, it can be generally said that SPSS regression and SEM would produce similar outcomes in this study.

The Cronbach's alpha test was performed to assess the reliability of the data (Table 2). All of the values were $>0.7$, implying internal consistency among the independent and dependent variables.

Table 2. Cronbach's alpha values.

\begin{tabular}{cc}
\hline Variable & Cronbach's Alpha \\
\hline Innovation & 0.75 \\
\hline Performance & 0.84 \\
\hline Social media sites & 0.81 \\
\hline
\end{tabular}

To test the hypotheses, a regression model was considered. The details are provided in Tables 3-9.

Table 3. Model summary for hypothesis H1.

\begin{tabular}{ccccc}
\hline Model & $\boldsymbol{R}$ & $\boldsymbol{R}$-Squared & Adjusted $\boldsymbol{R}$-Squared & Standard Error of the Estimate \\
\hline 1 & 0.421 & 0.837 & 0.008 & 1.433 \\
\hline
\end{tabular}


Table 4. The unstandardized and standardized coefficients for hypothesis H1.

\begin{tabular}{|c|c|c|c|c|c|c|}
\hline & \multirow{2}{*}{ Model } & \multicolumn{2}{|c|}{$\begin{array}{l}\text { Unstandardized } \\
\text { Coefficients }\end{array}$} & \multirow{2}{*}{$\begin{array}{c}\begin{array}{c}\text { Standardized } \\
\text { Coefficients }\end{array} \\
\text { Beta }\end{array}$} & \multirow[t]{2}{*}{$t$} & \multirow[t]{2}{*}{ Significance } \\
\hline & & B & $\begin{array}{l}\text { Standard } \\
\text { Error }\end{array}$ & & & \\
\hline & (Constant) & 2.916 & 0.448 & & 6.513 & 0.0001 \\
\hline 1 & $\begin{array}{l}\text { Social media platforms are an } \\
\text { important avenue for marketing } \\
\text { an enterprise's products. }\end{array}$ & 0.157 & 0.118 & 0.133 & 1.331 & 0.002 \\
\hline
\end{tabular}

Table 5. Model summary for hypothesis H2.

\begin{tabular}{ccccc}
\hline Model & $\boldsymbol{R}$ & $\boldsymbol{R}$-Squared & $\begin{array}{c}\text { Adjusted } \\
\boldsymbol{R} \text {-Squared }\end{array}$ & $\begin{array}{c}\text { Standard Error } \\
\text { of the Estimate }\end{array}$ \\
\hline 1 & 0.376 & 0.627 & 0.219 & 1.272 \\
\hline
\end{tabular}

Table 6. The unstandardized and standardized coefficients for hypothesis H2.

\begin{tabular}{|c|c|c|c|c|c|c|}
\hline & \multirow[b]{2}{*}{ Model } & \multicolumn{2}{|c|}{$\begin{array}{c}\text { Unstandardized } \\
\text { Coefficients }\end{array}$} & \multirow{2}{*}{$\begin{array}{c}\begin{array}{l}\text { Standardized } \\
\text { Coefficients }\end{array} \\
\text { Beta }\end{array}$} & \multirow{2}{*}{$t$} & \multirow{2}{*}{ Significance } \\
\hline & & B & $\begin{array}{c}\text { Standard } \\
\text { Error }\end{array}$ & & & \\
\hline & $1($ Constant $)$ & 1.778 & 0.342 & & 5.197 & 0.000 \\
\hline 1 & $\begin{array}{l}\text { Research and development } \\
\text { activity enhances innovation } \\
\text { for enterprises. }\end{array}$ & 0.507 & 0.095 & 0.476 & 5.360 & 0.000 \\
\hline
\end{tabular}

Table 7. Model summary for hypothesis H3.

\begin{tabular}{ccccc}
\hline Model & $\boldsymbol{R}$ & $\boldsymbol{R}$-Squared & $\begin{array}{c}\text { Adjusted } \\
\boldsymbol{R} \text {-Squared }\end{array}$ & $\begin{array}{c}\text { Standard Error } \\
\text { of the Estimate }\end{array}$ \\
\hline 1 & 0.316 & 0.66 & 0.251 & 1.245 \\
\hline
\end{tabular}


Table 8. The unstandardized and standardized coefficients for hypothesis H3.

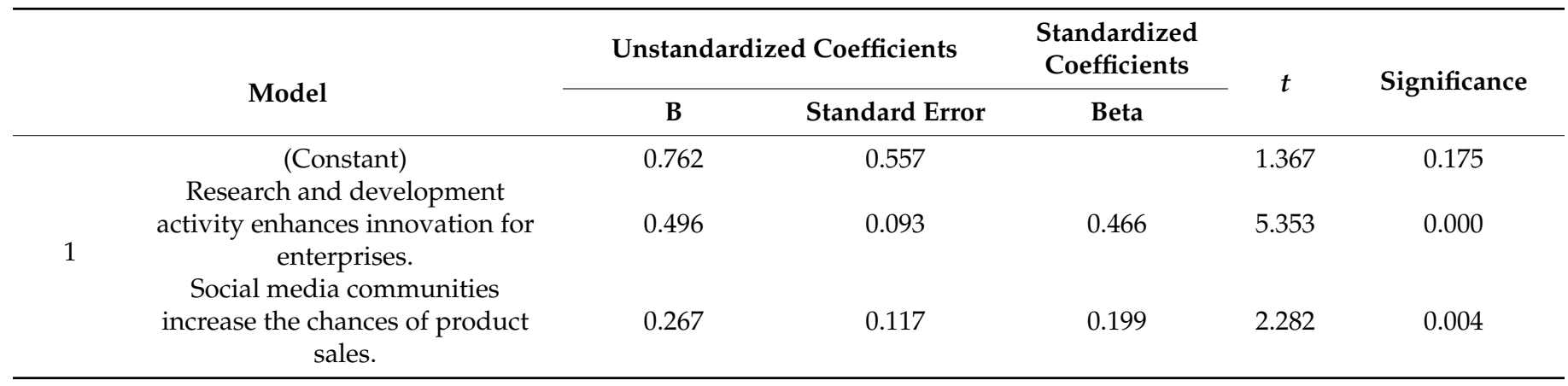

Table 9. Correlations between the independent and dependent variables.

\begin{tabular}{|c|c|c|c|c|}
\hline & & $\begin{array}{c}\text { Social Media } \\
\text { Performance Helps } \\
\text { Improve the Product } \\
\text { Marketing Time }\end{array}$ & $\begin{array}{c}\text { Social Media } \\
\text { Communities Increase } \\
\text { the Chances of Selling } \\
\text { Products }\end{array}$ & $\begin{array}{l}\text { Internal Knowledge Is } \\
\text { Important for Innovation }\end{array}$ \\
\hline \multirow{3}{*}{$\begin{array}{l}\text { Performance helps to } \\
\text { improve the product } \\
\text { marketing time, }\end{array}$} & Pearson's correlation & 1 & $0.222 *$ & $0.212 *$ \\
\hline & Significance (2-tailed) & & 0.026 & 0.034 \\
\hline & $N$ & 100 & 100 & 100 \\
\hline \multirow{3}{*}{$\begin{array}{l}\text { Social media communities } \\
\text { increase the chances of } \\
\text { selling products. }\end{array}$} & Pearson's correlation & $0.222 *$ & 1 & $0.494^{* *}$ \\
\hline & Significance (2-tailed) & 0.026 & & 0.000 \\
\hline & $N$ & 100 & 100 & 100 \\
\hline \multirow{3}{*}{$\begin{array}{l}\text { Internal knowledge is } \\
\text { important for innovation }\end{array}$} & Pearson's correlation & $0.212 *$ & $0.494^{* *}$ & 1 \\
\hline & Significance (2-tailed) & 0.034 & 0.000 & \\
\hline & $N$ & 100 & 100 & 100 \\
\hline
\end{tabular}

The value of $R$-squared was 0.8 , suggesting that the regression model was acceptable with a good fit. The level of significance was $<0.05$; thus, the null hypothesis was rejected. Accordingly, we inferred that social media platforms significantly affect innovation by enabling successful online marketing.

The value of $R$-squared was 0.6 , which implies that the model was able to explain $60 \%$ of the variance in the dependent variable. The level of significance for this model was $<0.05$; thus, the null hypothesis was rejected. Accordingly, we inferred that research and development activity impacts innovation in an enterprise.

This study also tested whether the use of social media influences performance by impacting entrepreneurial innovation. The results showed that there was a positive correlation between social media use and enterprise performance. The model was significant at the level of 0.05 .

A correlation test was performed to identify the relationship between the dependent and independent variables, which could be either positive or negative. The test results indicated a positive correlation between performance and innovation and between innovation and social media sites.

\section{Discussion}

The results demonstrate that innovation and social media sites have positive effects on the performance of enterprises in food sector within Kuwait. Thus, it is imperative that companies obtain and utilize both external and internal knowledge for further innovation. Pourkhani et al. [23] stated that social media is increasingly being used as an essential digital platform to maintain and develop connections, thus affecting entrepreneurial innovation. Furthermore, according to Voramontri and Klieb [24], social media platforms, such as Facebook and Twitter, provide a digital space where an enterprise can share pictures, be involved in professional networking, and indulge in microblogging. These activities directly influence innovation in enterprises. The current study found a direct correlation 
between innovation and social media sites, perhaps because these digital platforms enhance an enterprise's performance. The conversion of external knowledge to technology is possible only through innovation [25].

In a systematic review of studies conducted in multiple contexts (i.e., European countries, the United Kingdom (UK), and the US, Saura [11] stated that social media allows for developing brand communities through fan pages by increasing interaction between an enterprise and its customers. This current study's results also indicate that social media's benefits inspire an enterprise's innovation. However, there are also some disadvantages to using social media, such as the loss of potential customers due to delayed responses to their comments. According to Asio and Khorasani [42], social media creates platforms for exchanging knowledge, which, in turn, increase the innovative capacity of their users. This is compatible with the view of participant 1 in this study, who said that "using social media in business would create innovative ideas for my company." Likewise, participant 2 said that "social media platforms help me understand and meet the needs of consumers."

Nevertheless, participant 3 mentioned that "using social media needs to be specified in terms of defining ways to know whether we benefitted from using it." Indeed, such an opinion is compatible with McCann and Barlow's [43] statement that achieving the desired effects of social media on organizational performance requires considering how the metrics of consumers' responses to the company's social media presence are measured. Furthermore, companies must use metrics for measuring their return on investment from using social media.

Participant 4 said that his company "tries to minimize social media use, as employees do not like to spend additional time on it for work-related purposes" According to Evangeline and Ragavan [44], companies using social media to support innovation and performance should consider different variables, such as the culture of the organization because different types of organizations manifest various levels of resistance to change and adaptability in the use of social media. Based on Schniederjans et al.'s [45] findings, managers need to identify the type of organizational performance (i.e., financial vs. non-financial) enhancement to be achieved using social media. By doing so, decision makers in organizations can be be selective in choosing a proper social medial platform to communicate with current and potential customers.

Social media platforms are not designed for purchasing products; instead, they are forums where customers can gain valuable insights, and these insights are relevant factors in customers' decisions. Within the context of Indonesia, Moy et al. [7] stated that business enterprises use existing knowledge to transform innovative ideas into new technology. Within the domain of Australia, De Zubielqui et al. [26] considered openness and a collaborative approach to be drivers of innovation. The findings revealed that social media platforms facilitate openness to innovation. In Germany, Herden [36] observed that entrepreneurs who use social media develop a more dynamic approach and play a quintessential role in connecting the organization to the external world, which is consistent with the first hypothesis (i.e., social media's impact on entrepreneurial innovation) in the current study.

According to the knowledge-intensive entrepreneurship perspective, some enterprises have a dynamic entrepreneurial spirit that helps them utilize opportunities by combining external knowledge with internal knowledge to deliver innovation [20]. Along with intensive knowledge, digital ecosystems are an asset in process innovation. Social media plays an essential role in the digital ecosystem and the implementation of global business strategies. Global business strategy implementation has undergone many changes due to social media, which allows people to construct public and semi-public profiles within a systematic protocol [38]. Through this system, users can articulate their ideas and opinions and share a connection on a platform, as well as expand their base by connecting with mutual contacts [23]. Because of these platforms, business enterprises have the opportunity to communicate with stakeholders, including other businesses, public institutions, and consumers [17]. 
The theoretical framework of this study acknowledges the advantages of using social media innovation performance to measure the innovativeness of enterprises. The research design and the study findings allowed us to analyze gaps in the theoretical framework, while Section 6 provides insights into future innovation strategies and directions for future research.

\section{Conclusions}

This research has theoretical and practical implications. Theoretically, this study bridged the gap in the literature regarding the lack of studies focused on the role of social media in innovation capacity and organizational performance within the context of Kuwait. Practically, this study has implications for various stakeholders, primarily businesses, enterprises, and consumers. For business enterprises, understanding the role of social media and its double-edged effect on current and potential customers triggers the need to create a business plan that recognizes the impact of social media on their performance. Decision makers involved in developing such a business plan should consider identifying the various ways in which social media should be used to fulfil the objectives of the enterprise. Moreover, a monthly cash budget and budgeted income statements should be considered to examine the impact on income prior to and after adopting social media. This would enable enterprises to decide whether it is necessary to change or maintain their current methods of approaching markets. For customers, social media is a tool to express satisfaction/dissatisfaction with a specific enterprise's product(s). Such empowerment brings enterprises under a higher level of direct scrutiny by customers, who can use their comments to rank the performance of enterprises, and companies can use customer feedback to improve their performance.

The recent rise in creative innovation by entrepreneurs has led to increased awareness of digital marketing tools and aids. Organizations assimilate external knowledge from the virtual environment and internal knowledge to enhance their capacity. Management scholars consider this ability to be innovative because it allows organizations to gather knowledge from the external environment. Because of this cooperative and dynamic approach, most organizations can develop innovative ideas without in-house research. Consequently, this approach helps entrepreneurs cultivate innovation within either a new venture or a developed firm.

Understanding the importance of social media platforms as IT-related sources for innovation could drive agencies and policymakers to support Kuwaiti enterprises. This study's results reveal the positive role of social media use in entrepreneurial innovation. The findings emphasize the importance of implementing a sustainable online strategy. Strategy development should be performed by making small and limited investments and developing an extensive and steady network with enterprise stakeholders. Considering a partnership between a public institution or a business and consumers could be a potential future strategy. The primary goal of a business enterprise is to develop innovation to minimize cost and effort. There should be active cooperation between an enterprise and the external environment to achieve innovation and increase productivity and value. The innovation process should also be aligned to focus on attracting and cooperating with consumers.

Despite the contributions of this research, it has several limitations. As such, the findings of this study cannot be generalized reliably to the whole population since the sample is not representative of SMEs within Kuwait. The response rate of $26.04 \%$ adversely impacts the ability to generalize the findings to the whole population reliably. Another limitation is that the findings of this study only apply to SMEs in the food sector; accordingly, the findings cannot be generalized to other sectors of the Kuwaiti market.

Suggestions for future research include analyzing whether social media use among employees improves service and product innovation. Research could also be performed using a customer-based approach; it would be quite interesting to analyze the customer perspective as it relates to research and development practices. Furthermore, an analysis 
of enterprises could be developed by considering worthwhile case studies to provide a comprehensive picture of social media's influence on innovation. Additionally, dynamic enterprises within the purview of digital marketers need to be studied. Finally, the virtual environment plays a major role in enhancing innovation-led technology transfer and international cooperation for labor-intensive and knowledge-based enterprises. Further studies could focus on comparing the performance and results of these two types of enterprise.

Funding: This research received no external funding.

Institutional Review Board Statement: The study was conducted according to the guidelines of the Declaration of Helsinki and approved by the Institutional Review Board.

Informed Consent Statement: Written informed consent was obtained from the participants to publish this paper.

Data Availability Statement: Data available on request due to privacy/ethical restrictions.

Acknowledgments: The author would like to thank the Arab Open University-Kuwait (AOUKuwait) for guidance, encouragement, advice, and unlimited support.

Conflicts of Interest: The author declares no conflict of interest.

\author{
Abbreviations \\ small and medium-sized enterprises SMEs \\ computer-assisted qualitative data acquisition software CAQDAS
}

\title{
References
}

1. Chu, S.C.; Chen, H.T.; Gan, C. Consumers' engagement with corporate social responsibility (CSR) communication in so-cial media: Evidence from China and the United States. J. Bus. Res. 2020, 110, 260-271. [CrossRef]

2. Ebrahimi, P.; Hajmohammadi, A.; Khajeheian, D. Place branding and moderating role of social media. Curr. Issues Tour. 2020, 23, 1723-1731. [CrossRef]

3. Adeola, O.; Hinson, R.E.; Evans, O. Social media in marketing communications: A synthesis of successful strategies for the digital generation. In Digital Transformation in Business and Society; Palgrave Macmillan: Cham, Switzerland, 2020; pp. 61-81.

4. Lund, N.F.; Scarles, C.; Cohen, S.A. The Brand Value Continuum: Countering Co-destruction of Destination Branding in Social Media through Storytelling. J. Travel Res. 2020, 59, 1506-1521. [CrossRef]

5. Ahmad, S.Z.; Bakar, A.R.A.; Ahmad, N. Social media adoption and its impact on firm performance: The case of the UAE. Int. J. Entrep. Behav. Res. 2019, 25, 84-111. [CrossRef]

6. Cheing, A.; Hong, E.H.; Kuek, T.Y.; Chai, B.H.B.; Cham, T.H. Social Media Effectiveness Indicators of Microenterprise Strategic Planning. Asian J. Bus. Res. 2020, 10, 150. [CrossRef]

7. Moy, M.M.; Cahyadi, E.R.; Anggraeni, E. The Impact of Social Media on Knowledge Creation, Innovation, and Performance in Small and Medium Enterprises. Indones. J. Bus. Entrep. IJBE 2020, 6, 23. [CrossRef]

8. Seelos, C.; Mair, J. Mapping innovation pathologies. In Innovation and Scaling for Impact; Stanford University Press: Palo Alto, CA, USA, 2020; pp. 39-60.

9. Muninger, M.-I.; Hammedi, W.; Mahr, D. The value of social media for innovation: A capability perspective. J. Bus. Res. 2019, 95, 116-127. [CrossRef]

10. Uribe-Echeberria, R.; Igartua, J.I.; Lizarralde, R. Implementing Open Innovation in Research and Technology Organisations: Approaches and Impact. J. Open Innov. Technol. Mark. Complex. 2019, 5, 91. [CrossRef]

11. Saura, J.R. Using Data Sciences in Digital Marketing: Framework, methods, and performance metrics. J. Innov. Knowl. 2020, 6, 92-102. [CrossRef]

12. Michopoulou, E.; Moisa, D.G. Hotel social media metrics: The ROI dilemma. Int. J. Hosp. Manag. 2019, 76, 308-315. [CrossRef]

13. Chou, S.F.; Horng, J.S.; Liu, C.H.; Huang, Y.C.; Zhang, S.N. The critical criteria for innovation entrepreneurship of restaurants: Considering the interrelationship effect of human capital and competitive strategy a case study in Taiwan. J. Hosp. Tour. Manag. 2020, 42, 222-234. [CrossRef]

14. Buljubašić, T. Developing Innovation: Innovation Management in IT Companies; Walter de Gruyter GmbH \& Co KG: Berlin, Germany, 2020.

15. Zhan, Y.; Tan, K.H.; Chung, L.; Chen, L.; Xing, X. Leveraging social media in new product development: Organisational learning processes, mechanisms and evidence from China. Int. J. Oper. Prod. Manag. 2020, 40, 671-695. [CrossRef] 
16. Al-Mansour, J. The interrelationship between strategy as practice and public service innovation and delivery: Academic history and evidence from Kuwait. Int. J. Data Netw. Sci. 2021, 5, 151-162. [CrossRef]

17. Hoang, C.C.; Ngoc, B.H. The Relationship between Innovation Capability and Firm's Performance in Electronic Companies, Vietnam. J. Asian Financ. Econ. Bus. 2019, 6, 295-304. [CrossRef]

18. Olanrewaju, A.S.T.; Hossain, M.A.; Whiteside, N.; Mercieca, P. Social media and entrepreneurship research: A literature review. Int. J. Inf. Manag. 2020, 50, 90-110. [CrossRef]

19. Gieure, C.; del Mar Benavides-Espinosa, M.; Roig-Dobón, S. The entrepreneurial process: The link between intentions and behavior. J. Bus. Res. 2020, 112, 541-548. [CrossRef]

20. Alzougool, B. The use and continuance use of social media applications by small and medium enterprises in Kuwait. Glob. Knowl. Mem. Commun. 2019, 68, 471-490. [CrossRef]

21. Ali, A.; Bahadur, W.; Wang, N.; Luqman, A.; Khan, A.N. Improving team innovation performance: Role of social media and team knowledge management capabilities. Technol. Soc. 2020, 61, 101259. [CrossRef]

22. Yaqub, W.; Kakhidze, O.; Brockman, M.L.; Memon, N.; Patil, S. Effects of credibility indicators on social media news sharing intent. In Proceedings of the 2020 CHI Conference on Human Factors in Computing Systems (1-14), Honolulu, HI, USA, 25 April 2020.

23. Pourkhani, A.; Abdipour, K.H.; Baher, B.; Moslehpour, M. The impact of social media in business growth and performance: A scientometrics analysis. Int. J. Data Netw. Sci. 2019, 3, 223-244. [CrossRef]

24. Voramontri, D.; Klieb, L. Impact of social media on consumer behaviour. Int. J. Inf. Decis. Sci. 2019, 11, $209-233$.

25. Medase, S.K.; Abdul-Basit, S. External knowledge modes and firm-level innovation performance: Empirical evidence from sub-Saharan Africa. J. Innov. Knowl. 2020, 5, 81-95. [CrossRef]

26. De Zubielqui, G.C.; Fryges, H.; Jones, J. Social media, open innovation \& HRM: Implications for performance. Technol. Forecast. Soc. Chang. 2019, 144, 334-347. [CrossRef]

27. Daft, R.L.; Lengel, R.H. Organizational Information Requirements, Media Richness and Structural Design. Manag. Sci. 1986, 32, 554-571. [CrossRef]

28. Cheng, C.C.; Shiu, E.C. How to enhance SMEs customer involvement using social media: The role of Social CRM. Int. Small Bus. J. 2019, 37, 22-42. [CrossRef]

29. Alhaimer, R. Factors affecting SMEs owners to use social media for online advertisement in Kuwait. Int. J. Entrep. 2019, 23, 1-9.

30. Larson, E.; Vieregger, C. Strategic actions in a platform context: What should Facebook do next? J. Inf. Syst. Educ. 2019, 30, 97-105.

31. Kandiero, A.; Perpetua, T.; Jagero, D.N. Impact of access to social media on employee productivity and organisational performance at Econet Wireless Zimbabwe. Int. J. Knowl. Res. Manag. E Commer. 2014, 4, 25-32.

32. Bartosik-Purgat, M. Digital Marketing Communication from the Perspective of Individual Consumers: A Cross-Country Comparison. Entrep. Bus. Econ. Rev. 2019, 3, 205-220. [CrossRef]

33. Gomes, G.; Wojahn, R.M. Organizational learning capability, innovation, and performance: Study in small and medium-sized enterprises (SMES). Rev. Adm. São Paulo 2017, 52, 163-175. [CrossRef]

34. Lita, R.P.; Faisal, R.F.; Meuthia, M. Enhancing small and medium enterprises performance through innovation in Indonesia. $J$. Hosp. Tour. Technol. 2020, 11, 155-176.

35. Roberts, D.L.; Piller, F.T. Finding the right role for social media in innovation. MIT Sloan Manag. Rev. $2016,57,41$.

36. Herden, T.T. Explaining the competitive advantage generated from analytics with the knowledge-based view: The example of Logistics and Supply Chain Management. Bus. Res. 2019, 13, 1-52. [CrossRef]

37. Dinesh, K.K.; Sushil, P. Strategic innovation factors in startups: Results of a cross-case analysis of Indian startups. J. Glob. Bus. Adv. 2019, 12, 449-470. [CrossRef]

38. Toms, S.; Wilson, N.; Wright, M. Innovation, intermediation, and the nature of entrepreneurship: A historical perspective. Strateg. Entrep. J. 2020, 14, 105-121. [CrossRef]

39. Social Media in Kuwait, Statcounter, Global Stats. Available online: https://gs.statcounter.com/social-media-stats/all/kuwait (accessed on 2 June 2021).

40. Kuwait SMEs Post COVID-19: Current Situation, 16 July 2020, MARKAZ. Available online: https:/ /www.markaz.com/getmedia/ 653b185f-65b8-4fe7-8e62-3017f3e678c0/Note-on-Kuwait-SMEs-ENG-16-07-2020_1.pdf.aspx (accessed on 2 June 2021).

41. Sample Size Calculator, Qualtrics. Available online: https://www.qualtrics.com/blog/calculating-sample-size/ (accessed on 1 June 2021).

42. Asio, S.M.; Khorasani, S.T. Social media: A platform for innovation. In IIE Annual Conference. Proceedings; Institute of Industrial and Systems Engineers (IISE): Peachtree Corners, GA, USA, 2015; p. 1496.

43. McCann, M.; Barlow, A. Use and measurement of social media for SMEs. J. Small Bus. Enterp. Dev. 2015, 22, 273-287. [CrossRef]

44. Evangeline, E.T.; Ragavan, V.G. Organisational Culture and Motivation as Instigators for Employee Engagement. Indian J. Sci. Technol. 2016, 9, 1-4. [CrossRef]

45. Schniederjans, D.; Cao, E.S.; Schniederjans, M. Enhancing financial performance with social media: An impression management perspective. Decis. Support Syst. 2013, 55, 911-918. [CrossRef] 